\title{
Uso de diferentes estratégias na resolução de problemas
}

\section{Use of different troubleshooting strategies}

\author{
${ }^{1}$ Maria Madalena Dullius madalena@univates.br \\ ${ }^{1}$ Ana Paula Krein Müller \\ ${ }^{1}$ Vanessa Paula Reginatto \\ ${ }^{1}$ Júlia Weber Ferreira da Silva
}

\section{RESUMO}

O estudo da matemática tem se mostrado cada vez mais desgostoso por parte dos estudantes que aparentam desmotivados quando precisam resolver problemas referentes à disciplina. Muitos alegam que, pela necessidade de se chegar à perfeição com cálculos e fórmulas, o conteúdo se torna difícil e tedioso. Assim, perguntamo-nos: E esse problema tem solução? Neste artigo apresentamos os resultados de uma investigação sobre a exploração de diferentes estratégias de resolução de problemas como um meio de se chegar a uma solução. Para chegarmos a esse quadro, realizamos intervenções com estudantes do $5^{\circ}$ ano do Ensino Fundamental em quatro escolas do Vale do Taquari. Aplicamos questionários nos quais os estudantes deveriam resolver os problemas de forma aleatória, sem terem a obrigação do uso do cálculo formal, que é normalmente empregado pelos mesmos por ser o mais exigido e ensinado. A partir da resolução desses problemas, analisamos e elencamos em categorias cada uma, separando os acertos dos erros. Como resultados, observamos que muitos estudantes preferem não apresentar o desenvolvimento da resolução, apenas marcam a opção que acreditam ser coerente, e desses, grande parte não obteve êxito. Alguns ousaram mais e fizeram tabelas e desenhos como forma de resolução, e desses, todos acertaram. Concluímos que é muito importante para o estudante saber refletir e pensar sobre o que ele está fazendo ao invés de copiar mecanicamente o que o professor ensina, e aqueles que passaram a ousar com diferentes meios para a resolução de seus problemas também se sentiram mais motivados a continuar aprendendo.

Palavras-chave: Ensino da matemática. Diferentes estratégias. Resolução de problemas.

\begin{abstract}
The study of mathematics has been increasingly disgusted by students who appear unmotivated when they need to solve problems related to the subject. Many contend that, by the necessity of perfection with calculations and formulas, the content becomes difficult and tedious. So we ask ourselves: And this problem has a solution? In this article we present the results of an investigation about the exploration of different strategies of problem solving as a means of reaching a solution. To reach this picture, we carried out interventions with students of the 5th year of elementary school in four schools in the Taquari Valley. We applied questionnaires in which students should solve problems at random, without having to use the formal calculus, which is normally used by them as being the most demanded and taught. From the resolution of these problems, we analyze and categorize each one, separating the correct answers from the errors. As results, we observed that many students prefer not to present the development of the resolution, only mark the option that they believe to be coherent, and of these, much was not successful. Some dared more and made tables and drawings as a form of resolution, and of these, all got it right. We conclude that it is very important for the student to know how to reflect and think about what he is doing instead of mechanically copying what the teacher teaches, and those who have dared to use different means to solve their problems also felt more motivated to continue to learn.
\end{abstract}

Keywords: Teaching of mathematics. Different strategies. Problem solving. 


\section{INTRODUÇÃO}

Vivemos em um tempo que nossos estudantes exigem que nossas aulas sejam cada vez mais criativas e bem elaboradas, além disso, nossas escolas continuam com modelos e estruturas tradicionais, nessa perspectiva a matemática geralmente é considerada uma disciplina difícil pelos estudantes e atualmente é uma recorrente inquietação dos professores, no que diz respeito ao desempenho escolar. Os números divulgados pelos meios de comunicação apresentam indicativos da preocupante situação em que se encontra a aprendizagem da Matemática, tanto no Rio Grande do Sul quanto no Brasil. Diante desta situação, tem-se como desafio, melhorar a qualidade da educação de nossos estudantes, logo, é necessário ter claro o que se quer no aprendizado dos mesmos e como ensinar para que isso realmente aconteça.

Associar o cotidiano dos estudantes ao conteúdo trabalhado em sala de aula pode possibilitar um maior engajamento dos mesmos, além de estarmos vivenciando e praticando situações reais com eles. A resolução de problemas é apontada pelos Parâmetros Curriculares Nacionais (PCNs) (BRASIL, 1998, p. 40) como ponto de partida da atividade matemática, oferecendo ao estudante a oportunidade de "mobilizar conhecimentos e desenvolver a capacidade para gerenciar as informações que estão ao seu alcance”.

Considerando que a resolução de um problema implica na compreensão do que foi proposto e na apresentação de respostas aplicando procedimentos adequados, cabe ressaltar que existem vários caminhos para se chegar a um mesmo resultado, ou seja, inúmeras são as estratégias que o estudante pode utilizar nesse processo. A temática das estratégias que podem ser utilizadas na resolução de problemas matemáticos nos sensibiliza já que percebemos, em nossa trajetória docente, a facilidade com que alguns estudantes, quando permitidos, resolvem determinados problemas utilizando-se de estratégias alternativas, mesmo que conteúdos específicos estejam em desenvolvimento. Nestes casos, é comum justificarem que consideram mais fácil resolver de tal forma, que o cálculo formal é mais trabalhoso e geralmente, suas resoluções são coerentes com o problema proposto.

Considerando este contexto, buscamos investigar as diferentes estratégias que estudantes do $5^{\circ}$ ano utilizam ao resolverem problemas matemáticos. A investigação faz parte da pesquisa desenvolvida na Univates no âmbito do Programa Observatório da Educação. Sendo assim destacamos o objetivo de desenvolver atividades que auxiliam os estudantes do $5^{\circ}$ ano das escolas parceiras ao projeto a familiarizar-se com a resolução de problemas, preocupado principalmente em explorar com estes estudantes diferentes estratégias utilizadas para a resolução destes.

As diferentes estratégias utilizadas pelos estudantes devem ser analisadas para que possamos visualizar, entender, identificar e compreender como foram utilizadas. A luz destas ideias, propusemos as escolas parceiras desenvolver atividades com estudantes do $5^{\circ}$ ano do Ensino Fundamental, com o intuito de explorar e incentivar a utilização de diferentes estratégias de resolução de problemas, buscando contribuir para melhoria do processo de ensino e aprendizagem da Matemática, e mais do que isso, auxiliar no desenvolvimento da capacidade de tomada de decisões, autonomia e de resolver situações cotidianas que possam vir a ocorrer.

\section{FUNDAMENTAÇÃO TEÓRICA}

\section{1 Ensino da matemática}

Atualmente o ensino da matemática vem nos exigindo mudanças, assim cabe um repensar nas práticas docentes e também nas concepções de ensino e aprendizagem. Nesta perspectiva compete ao professor o papel de mediador e facilitador, procurando estimular o estudante a criar estratégias para situações problemáticas do cotidiano. Dante, ressalta que: 
[...] um caminho bastante razoável é preparar o aluno para lidar com situações novas, quaisquer que sejam elas. E, para isso, é fundamental desenvolver nele iniciativa, espírito explorador, criatividade e independência, através da resolução de problemas. (DANTE, 2002, p. 12).

De acordo com a Matriz de Referência do SAEB e da Prova Brasil, as avaliações fornecem indicadores a respeito da qualidade da educação brasileira, estruturadas com foco em resolução de problemas, destaca que "o conhecimento matemático, ganha significado, quando os estudantes têm situações desafiadoras quando resolvem e trabalham para desenvolver estratégias de resolução" (BRASIL, 2008, p. 106). Estas avaliações externas têm gerado preocupação aos professores e gestores das escolas, visto que os índices apresentados apontam o mau êxito do ensino de Matemática em nossas escolas.

Além disso, os Parâmetros Curriculares Nacionais (PCNs) (BRASIL, 1998) destacam a resolução de problemas como início da atividade matemática em contrapartida à simples resolução de procedimentos e ao acúmulo de informações, uma vez que possibilita aos estudantes a mobilização dos conhecimentos e o gerenciamento das informações que estão ao seu alcance. A capacidade de resolver problemas é vista por muitos educadores matemáticos como um dos principais objetivos do processo de ensino e aprendizagem da Matemática.

O método de ensino focado na resolução de problemas está associado ao "fazer matemática” e não apenas observá-la, exigindo mais habilidades do professor. Conforme Dante (2002), a resolução de problemas é uma tarefa muito mais complexa do que ensinar algoritmos e equações. O professor é visto como orientador enquanto ensina algoritmos e equações, já na resolução de problemas ele atua como incentivador e moderador das ideias dos estudantes.

\section{2 Resolução de problemas}

Considerada como metodologia de ensino a resolução de problemas pode auxiliar e aprimorar o ensino de Matemática, aproximando a realidade com o conhecimento matemático. Conforme apresentado por Alves (2006, p.23).

A proposta de Resolução de Problemas é apontada pelos educadores matemáticos como ponto de partida para a atividade matemática, baseando-se no princípio de que o conhecimento ganha significado quando o aluno se envolve com situações desafiadoras nas quais trabalha para desenvolver estratégias de resolução.

Inicialmente, a matemática nas escolas era tratada apenas com decorebas e repetição como modo de aprendizagem. Com o passar dos anos, ao tentar mudar essa didática, foi implementada a matemática com exageros de complexidade e símbolos matemáticos, porém era muito abstrata para o cotidiano e sem um princípio. Sendo assim, a partir dos anos 80, a resolução de problemas teve sua devida importância passando a ser considerada como principal foco do ensino da matemática, pois sabemos que mutuamente o estudante aprende matemática resolvendo problemas e para resolvê-los.

Segundo Pozo (1998) ensinar a resolução de problemas pode possibilitar aos estudantes “a capacidade de aprender a aprender, no sentido de habituá-los a encontrar por si mesmos, respostas às perguntas que os inquietam ou que precisam responder”. Portanto para que essa capacidade se torne possível, é necessário que o professor explore diferentes problemas, e não somente repetição de exercícios. Ainda nessa perspectiva, Dante destaca:

“É preciso fazer clara distinção entre o que é um exercício e o que é um problema. Exercício, como o próprio nome já diz, serve para exercitar, para praticar um determinado algoritmo ou processo (...). Problema ou problema-processo, (...) é a descrição de uma situação onde se procura algo desconhecido e não se tem previamente nenhum algoritmo que garanta sua solução”. (DANTE, 2002, p 43). 
Vale ressaltar que a resolução de problemas necessita de um caminho ou de vários caminhos para alcançar o objetivo e é nestes caminhos que se encontram as riquezas das diferentes estratégias utilizadas pelos estudantes, conforme Polya:

\begin{abstract}
"Resolver um problema é encontrar os meios desconhecidos para um fim nitidamente imaginado. Se o fim por si só não sugere os meios, se por isso temos de procurá-los refletindo conscientemente sobre como alcançar o fim, temos um problema. Resolver um problema é encontrar um caminho onde nenhum outro é conhecido de antemão, encontrar um caminho a partir de uma dificuldade, encontrar um caminho que contorne um obstáculo, para alcançar um fim desejado, mas não alcançável imediatamente, por meios adequados”. (POLYA apud DANTE 2010, p. 1)
\end{abstract}

Nesta perspectiva, destacamos as diferentes estratégias de resolução de problemas utilizadas pelos estudantes nesta pesquisa, dentre estas, classificamos como cálculo formal, eliminação, organizar padrões e desenho.

\title{
2. 3 Diferentes estratégias de resolução de problemas
}

A resolução de problemas matemáticos pode estar associada a utilização de diferentes estratégias. Neste artigo aborda-se as quatro estratégias empregadas pelos estudantes, o cálculo formal, a eliminação, o desenho e organizar padrões. Entretanto sabe-se que vários autores apresentam outras formas de resoluções, além das que são mencionadas neste artigo.

Sendo assim, sabemos que cada estudante busca uma forma de obter o resultado correto, muitas vezes diferenciado do cálculo formal e que até impressiona o professor: "Para muitos professores, pode parecer incomum a maneira como as crianças resolveram o problema (...)” (SMOLE e DINIZ, 2001, p. 122)

“(...) um olhar mais voltado para o processo e o raciocínio utilizado pelas crianças revela-nos que elas estão em busca de um caminho próprio e que resolver um problema, nesse momento, está muito longe da tarefa de identificação do algoritmo que solucione a situação apresentada. Para elas, não é estranho fazer um desenho na tentativa de encontrar uma solução; muito pelo contrário, tal ação surge naturalmente, sendo vista como um caminho viável para se chegar à solução".

As soluções para os problemas possibilitam o desenvolvimento de diferentes estratégias de resolução, da linguagem e da interpretação. O processo, o registro pela escrita e oralidade, deve ter igual ou maior importância que o resultado final. Encontrar o resultado faz parte do processo. E a melhor estratégia durante a resolução do problema pode determinar, em melhor tempo, uma solução criativa e interessante. Mesmo não sendo momento de discutir sobre a ação do professor, não podemos deixar ao esquecimento seu posicionamento nesta perspectiva didática.

\subsubsection{Cálculo formal}

O cálculo formal foi a estratégia que os estudantes mais utilizaram, isto talvez se deva pelo fato de que esta seja a metodologia mais exigida pelos professores dessas turmas. Entende-se por cálculo formal um conjunto de expressões que apresentam regras e fórmulas algébricas, no qual o estudante reproduz um esquema similar ao que lhe foi apresentado. Segundo Treffers (apud GONÇALVES 2008, p. 20) existem três níveis que o estudante pode desenvolver durante o período escolar.

- Cálculo por contagem - apoiado, se necessário, em materiais que permitam a contagem;

- Cálculo por estruturação - cálculo não baseado contagem por modelos adequados; 
O uso de cada nível desta estratégia de resolução de problemas pode estar associado aos níveis de aprendizado de cada estudante, o que também pode levar o mesmo a fazer o cálculo mental, sem escrevê-lo na questão, no qual acabamos classificando com somente resposta. Outra questão que devemos enfatizar é o fato de ainda temos bem forte que o ensino e a aprendizagem da matemática estão diretamente associados a cálculos algébricos com fórmulas e esquemas a serem seguidos.

\subsubsection{Eliminação}

Uma das estratégias utilizadas pelos estudantes foi a eliminação, como todas as questões da prova Brasil tem cinco alternativas, isto possibilita o uso de tal estratégia. Segundo Furlanetto (2013), o estudante pode analisar as possíveis respostas e descartar algumas alternativas seguindo critérios por ele estabelecidos. Ainda conforme o autor a eliminação é uma estratégia que “(...) tem potencial de demonstrar-se eficaz em problemas de múltipla escolha, onde o resolvedor precisa estabelecer critérios e eliminar alternativas que não se enquadrem nos mesmos.” (FURLANETTO, 2013, p. 68).

Sendo assim, se pode considerar a estratégia de eliminação um modo de descobrir a resposta final sem ter a necessidade de fazer cálculos, apenas observando a situação problema e as suas possíveis respostas.

\subsubsection{Desenho}

Encontrar soluções pode provocar o desenvolvimento de estratégias de resolução, da linguagem e a interpretação de informações dos problemas. Também observamos o uso do desenho como estratégia em algumas resoluções desenvolvidas pelos estudantes, segundo Cavalcanti (2001, p. 128)

\footnotetext{
"Quando desenham, elas explicitam mais facilmente os significados presentes no texto - palavras, cenas, informações, operações, etc. - e assim constroem uma representação mental dos mesmos. O desenho também fornece ao professor pistas sobre a criança, como ela pensou e agiu para solucionar determinado problema, e à criança fornece um meio de manifestar como age sobre o problema, como expressa suas ideias e comunica-se.”
}

Segundo Smole e Diniz (2001), a estratégia de desenho pode ser dividida em três etapas, estas identificam características do enunciado, a resolução com apenas desenho e por fim mescla o resultado final entre símbolos matemáticos e desenhos, conforme segue:

\footnotetext{
"Estudos diversos indicam que o desenho pode ser utilizado de três maneiras diferentes na resolução de problemas. Em uma primeira etapa, o resolvedor utiliza o desenho para representar aspectos da situação apresentada no texto, mas não expressa relações que identifiquem as transformações numéricas, ou que indiquem que estivesse resolvendo o problema através do desenho. (...) Em uma segunda etapa, o resolvedor consegue representar a resolução completa do problema utilizando apenas o desenho (...). Finalmente, na terceira etapa, o resolvedor começa a misturar desenhos e sinais matemáticos.” (SMOLE e DINIZ, p. 128).
}

Assim o uso de diferentes estratégias pode estar associado a metodologia utilizada pelo professor, é válido ressaltar que as diferentes formas de resolver um problema podem apresentar uma riqueza de caminhos, fazendo os estudantes aprenderem diferentes estratégias na interação com seus colegas.

\subsubsection{Organizar padrões}

A estratégia de organizar padrões também foi encontrada na resolução das questões desenvolvidas com os estudantes, ela possibilita o desenvolvimento da capacidade de generalizações, proporcionando descobertas elaborando conceitos matemáticos que tornam claro sua lei de formação, assim concordando com Vale, Palhares, Cabrita e Boralho, organizar padrões apoia os estudantes a descobrir relações, generalizações, previsões e fazer generalizações: 
“Quando apelamos aos padrões no ensino da matemática é normalmente porque queremos ajudar os alunos a aprender uma matemática significativa e/ou a envolver-se na sua aprendizagem, facultando-lhes um ambiente de aprendizagem que tenha algo a ver com a sua realidade e experiências. $\mathrm{O}$ estudo de padrões vai de [ao] encontro a este aspecto, apoiando a aprendizagem dos estudantes para descobrirem relações, encontrarem conexões, fazerem generalizações e também previsões.” (VALE; PALHARES; CABRITA; BORRALHO, 2006, p. 197).

A utilização da estratégia de padrões é percebida quando as formas e os números são colocados numa sequência que se repete. Ao nosso entorno pode-se identificar vários padrões diferentes, que podem nos ajudar a compreender o mundo. O ensino e aprendizagem da matemática podem estar centrados na utilização de padrões. Sendo que quando desenvolve-se esta estratégia ajuda-se os estudantes a ordenar em grupos, combinar os semelhantes e descobrir como se combinam.

\section{METODOLOGIA}

Com o intuito de atingirmos os objetivos propostos pelo projeto que consiste em contribuir com a melhoria do ensino e aprendizagem da Matemática, propomos a realização de atividades que possam auxiliar os estudantes das seis escolas parceiras. Inicialmente conversamos com as respectivas professoras para analisar a possibilidade dos pesquisadores realizarem intervenções com o $5^{\circ}$ Ano do Ensino Fundamental. Esta série foi escolhida devido ao fato desta ser uma das turmas onde será aplicada a Prova Brasil, ano de 2013, em todas as escolas públicas e privadas, para avaliar o Índice de Desenvolvimento da Educação Básica (IDEB).

Obtivemos um retorno de quatro escolas que demonstraram interesse no desenvolvimento da intervenção. Neste contexto, assessoramos um total de cinco turmas, no qual construímos um cronograma mensal para o atendimento das mesmas, sendo organizado de acordo com a disponibilidade das escolas. Cada encontro teve aproximadamente a duração de duas horas aula, em que foram abordadas e exploradas questões das avaliações externas que já ocorreram em anos anteriores. Essas ocorreram de maio até outubro de 2013, podendo variar de cinco a seis intervenções por escola.

O material trabalhado nas escolas foi organizado e aplicado pela equipe de pesquisadores do projeto. Após cada intervenção corrigimos e analisamos as resoluções, observando o desenvolvimento e as estratégias utilizadas pelos estudantes. Em cada encontro abordou-se desafios matemáticas ou dinâmicas, objetivando estimular os estudantes para a prática de resolução de problemas. Na sequência, devolvemos as questões corrigidas para verificar seu desempenho e assim exploramos com os estudantes as diferentes possibilidades de resolução apresentadas por eles. Ainda propomos outro questionário elaborado previamente com problemas que foram escolhidos com o propósito de abordar as dificuldades apresentadas anteriormente.

Para a coleta de dados, todo o material produzido, foi organizado em portfólios individuais utilizando uma revista antiga nas quais foram coladas as atividades desenvolvidas. Neste artigo apresentamos a análise de três encontros, sendo que o primeiro contou com duas questões, o segundo com três, assim como o terceiro. Para auxiliar o processo de análise, as questões da primeira intervenção foram nomeadas como A1 e A2, as da segunda como B1, B2 e B3, e, consequentemente, a terceira como C1, C2 e C3. As atividades foram propostas para cinco turmas em escolas de Educação Básica do Vale do Taquari somando um total de 80 estudantes, dos quais 28 pertencem a uma turma que não resolveu o questionário do terceiro encontro.

Após o desenvolvimento das atividades nas escolas realizamos uma análise buscando identificar quais as principais estratégias empregadas pelos estudantes na resolução das questões, categorizando-as conforme as estratégias utilizadas em cálculo formal, desenho, só resposta, não respondeu, organizar padrões, tabelas e gráficos. Percebemos que algumas estratégias como trabalhar em sentido inverso, reduzir a unidade e tentativa e erro, não foram utilizadas, isso talvez se deva ao fato das questões não exigirem tais estratégias. 


\section{ANÁLISE DAS ESTRATÉGIAS}

Apresentamos a seguir as questões exploradas, juntamente com as análises das estratégias, bem como alguns recortes com as resoluções realizadas pelos estudantes.

Questão A1 - A tabela abaixo mostra a data de nascimento de quatro alunos.

\begin{tabular}{cccc}
\hline & & Data de nascimento & \\
Nomes & Dia & Mês & Ano \\
\hline Márcia & 7 & Abril & 1998 \\
Alex & 12 & Abril & 1998 \\
Samuel & 26 & Abril & 1998 \\
Aline & 15 & Abril & 1998 \\
\hline
\end{tabular}

De acordo com os dados apresentados o mais jovem é?
a) Márcia
b) Alex
c) Aline
d) Samuel

Nesta questão destacamos a importância de localização de datas do estudante na qual é necessário ter o conhecimento prévio de que o maior número representa o nascimento mais tardio. Percebemos que os mesmos apresentaram dificuldades em identificar que a maior data representava o mais jovem, a maioria dos estudantes marcou a dia 7 de abril, o que podemos observar que eles associaram a menor data com o mais novo.

Nesta questão destaca-se que 50\% dos estudantes utilizaram a estratégia de organizar padrões para resolver o problema, sendo que destas a maioria obteve êxito. Já os outros 50\% não apresentaram o desenvolvimento da resposta e poucos alcançaram o resultado desejado. Na resolução do estudante 20 apresentada na Figura 1, percebe-se a utilização da estratégia de organizar padrões.

\section{Figura 1 - Resolução do estudante número 20.}

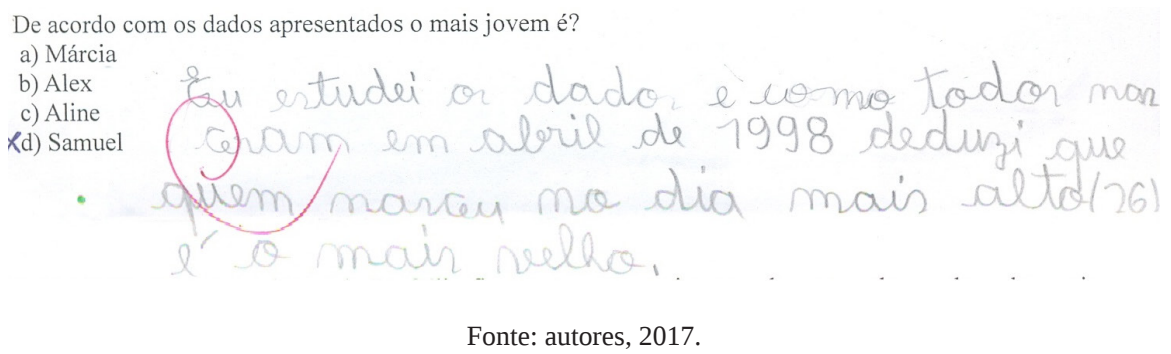

Questão A2 - No final de ano, os alunos de D. Célia fizeram uma pesquisa na sala, para saber onde cada um ia passar as férias. Cada aluno podia escolher um só lugar. 
Este gráfico mostra o resultado da pesquisa:

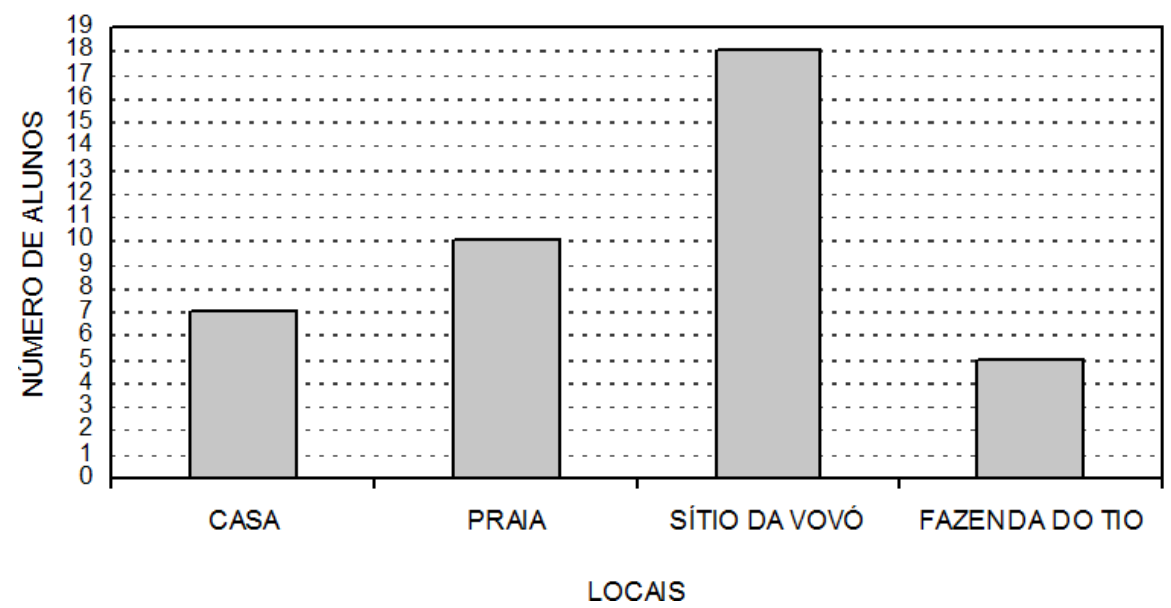

Qual dos locais foi MENOS escolhido pelos alunos para passarem as férias?
a) Casa
b) Fazenda do tio
c) Praia
d) Sítio da vovó

Nesta questão o estudante necessita realizar a interpretação do que está sendo solicitado, tendo o cuidado para não se precipitar e responder por impulso, pois sabe-se que normalmente em questões de identificação dos elementos do gráfico pede-se que se marque o item que mais aparece.

Constatou-se que $93 \%$ dos estudantes acertaram a questão, podendo assim ser considerada fácil para este nível de ensino. Destaca-se que 53\% das respostas foram desenvolvidas utilizando a estratégia de organizar padrões, e a maioria dos estudantes obtiveram êxito nesta resolução.

Questão B1 - Maria limpando sua bolsa encontrou as seguintes notas e moedas:

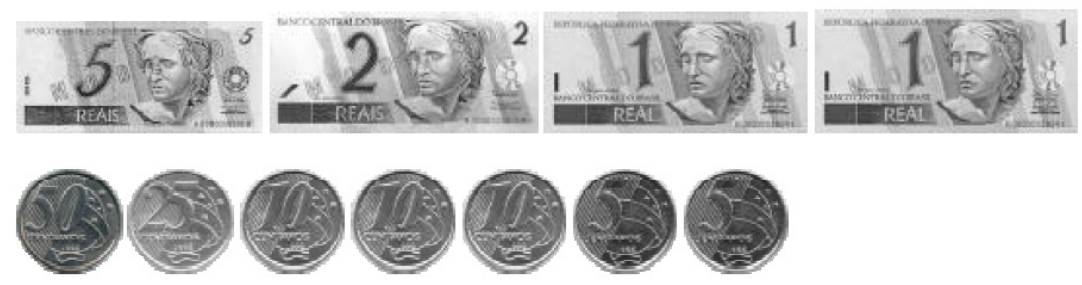

Quantos reais ela tinha na sua bolsa?
a) $\mathrm{R} \$ 9,00$
b) $\mathrm{R} \$ 9,90$
c) $\mathrm{R} \$ 10,10$
d) $\mathrm{R} \$ 10,15$

Nesta questão o estudante precisa apenas interpretar os valores e realizar a relação com a escrita do número decimal, podendo fazer um cálculo básico ou até mesmo somente realizar a contagem, cuidando para diferenciar as dezenas e as unidades. Destaca-se que os estudantes na maioria optaram por apenas resposta. Isso se deve ao fato da questão ser basicamente desenhada, facilitando a visualização do problema e da possível resposta. O outro tipo de resolução de problema utilizado foi o cálculo, pois a partir dos valores apresentados, o estudante pode somar quanto dinheiro Maria possuía.

Observa-se nas resoluções dos estudantes a utilização da estratégia do cálculo formal, nelas destaca-se a compreensão do número decimal e as diferentes formas de organizar os cálculos formais. Salientamos que na resolução do estudante de número 30, em que fez marcações no desenho para se localizar na contagem. 
Figura 2 - Resolução do estudante número 30

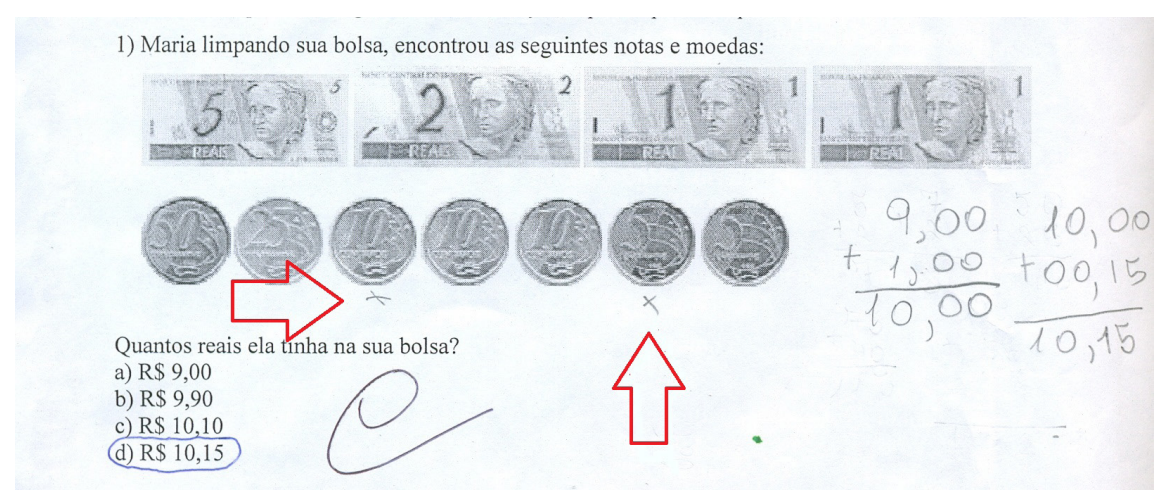

Fonte: autores, 2017.

Questão B2 - No fim do mês, Marcelo verificou quantas calças de cada numeração havia em sua loja e fez um gráfico.

Estoque de calças - Loja do Marcelo

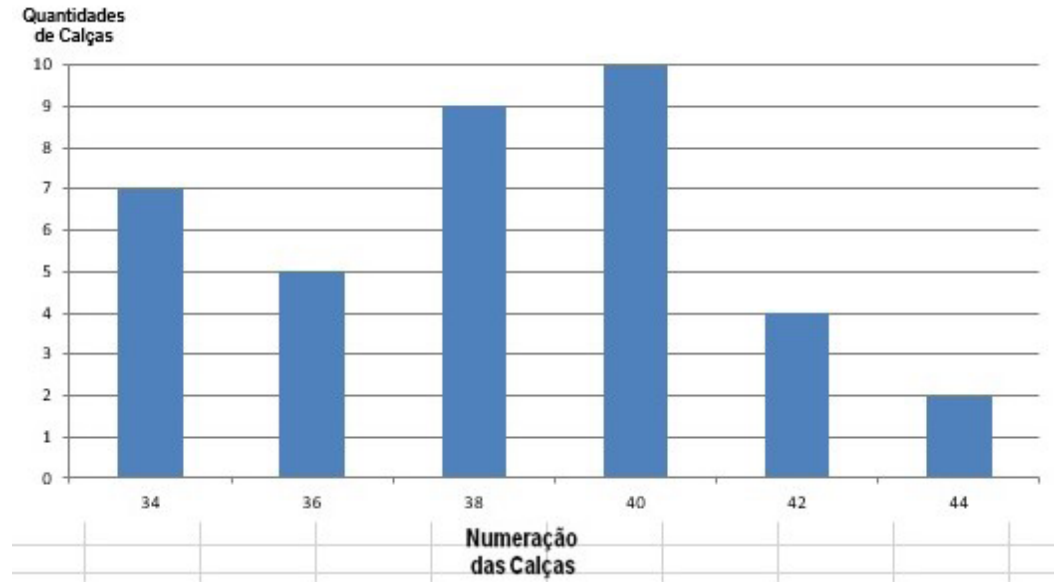

Quais numerações possuíam a menor quantidade de calças em estoque naquela data?
a) 34 e 36
b) 38 e 40
c) 42 e 44
d) 38 e 44

Nesta questão o estudante precisa fazer a interpretação do gráfico, relacionando a quantidade de calças com a sua numeração, estando implícito o cruzamento de dados entre os eixos. Observamos que todos os estudantes marcaram só resposta por ser uma questão de análise gráfica, sem necessidade de cálculos ou desenhos mais complexos.

Questão B3 - Faltam 31 dias para o aniversário de João. Quantas semanas completas faltam para o aniversário dele?
a) 3
b) 4
c) 5
d) 6

Nesta questão o estudante deve possuir o conhecimento prévio de tempo para saber que cada semana tem 7 dias e a partir desse dado, calcular quantas semanas cabem em 31 dias. Pensando nisso, o aluno deveria concluir que em 28 dias há 4 vezes 7 dias, por isso, faltam 4 semanas completas para o aniversário de João. 
A partir da tabela, observados que a maioria dos estudantes apenas marcou a resposta da questão, sem apresentar números e desenvolvimentos da resposta, provavelmente por terem calculado mentalmente. Entretanto, podemos observar que com esse método, muitos erraram a questão. Diferente dos que resolveram a mesma questão por cálculo formal, na qual todos acertaram.

Questão C1 - Roberto correu a Maratona da Pampulha em 2008. Ele fez o percurso em 1 hora e 47 minutos. Qual foi o tempo em minutos gasto por Roberto para completar essa maratona?
a) 100 minutos.
b) 107 minutos.
c) 117 minutos.
d) 147 minutos

Neste problema os estudantes também devem ter o entendimento prévio de que, para calcular o total de minutos para percorrer a maratona, deve-se saber que cada 1 hora possui 60 minutos. Com esse dado, somar aos 47 minutos.

Observamos que os tipos de resoluções foram os mais variados possíveis. Os estudantes que apenas marcaram a resposta foram os que tiveram maior percentual de erro. Os que organizaram padrões, como, assumindo que 1 hora tem 60 minutos e somando com o restante foram os que obtiveram maior percentual de acerto. Ainda houve aqueles que fizeram o cálculo e que desenharam uma tabela para descobrir o valor.

Tem-se bem claro na resolução do estudante de número 3 a utilização da estratégia de organizar padrões, o mesmo fez relações para obter o resultado, partindo de um dado conhecido.

\section{Figura 3 - Resolução do estudante número 3}

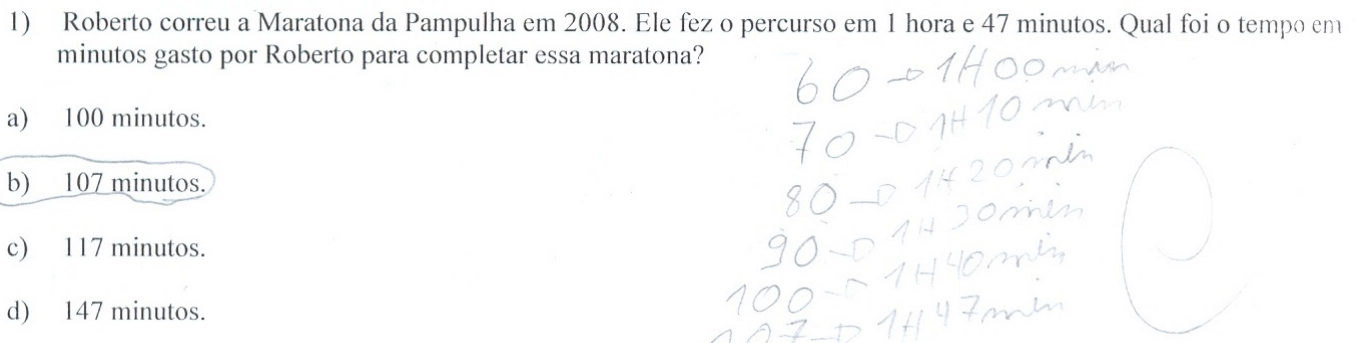

Fonte: autores, 2017

Questão C2 - No mês passado, a conta de luz da casa de Pedro foi de R\$ 76,35. Neste mês, sua conta de luz foi de R \$ 67,45. Quanto Pedro pagou a menos de um mês para outro?
a) $\mathrm{R} \$ 18,90$
b) $\mathrm{R} \$ 11,10$
c) $\mathrm{R} \$ 9,10$
d) $\mathrm{R} \$ 8,90$

Nessa questão o estudante deve fazer um cálculo de subtração com números com vírgula. Para descobrir o resultado, deve-se subtrair a conta do mês passado à conta deste mês, obtendo assim, o resultado. Destacamos que a maioria dos estudantes tiveram êxito na questão e a resolveram pelo cálculo formal. Alguns ainda optaram por só marcar a resposta, e mesmo estes, também acertaram a questão. 
Questão C3 - Marcelo fez a seguinte planta da sua sala de aula.

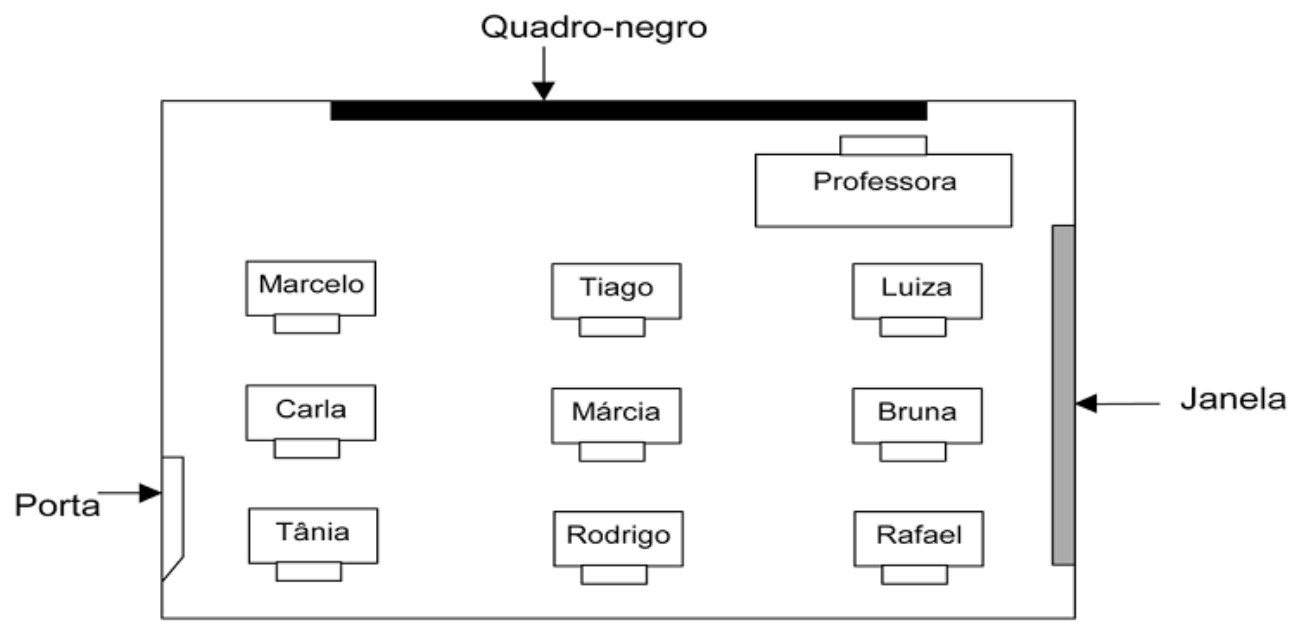

Das crianças que se sentam perto da janela, a que senta mais longe da professora é:
a) O Marcelo.
b) A Luiza.
c) O Rafael.
d) A Tânia

Na última questão os estudantes deveriam observar o desenho para descobrir qual deles que, situado ao lado da janela, senta mais longe da professora. Para isso, os estudantes só precisam determinar o lado que se encontra a janela e assim, ver qual está mais para o fundo da sala, ou seja, longe da professora. A maioria dos estudantes só marcou a resposta pois fez uma simples observação do desenho. Os que organizaram padrões foram os que disseram na folha de resposta que haviam marcado aquela opção pois era o que viam.

Na resolução do estudante de número 8 percebe-se claramente a utilização da estratégia de eliminação, como demostra a escrita deste. Porém este não considerou a característica “sentar perto da janela”, o que resultou numa eliminação equivocada.

\section{Figura 4 - Resolução do estudante número 8}

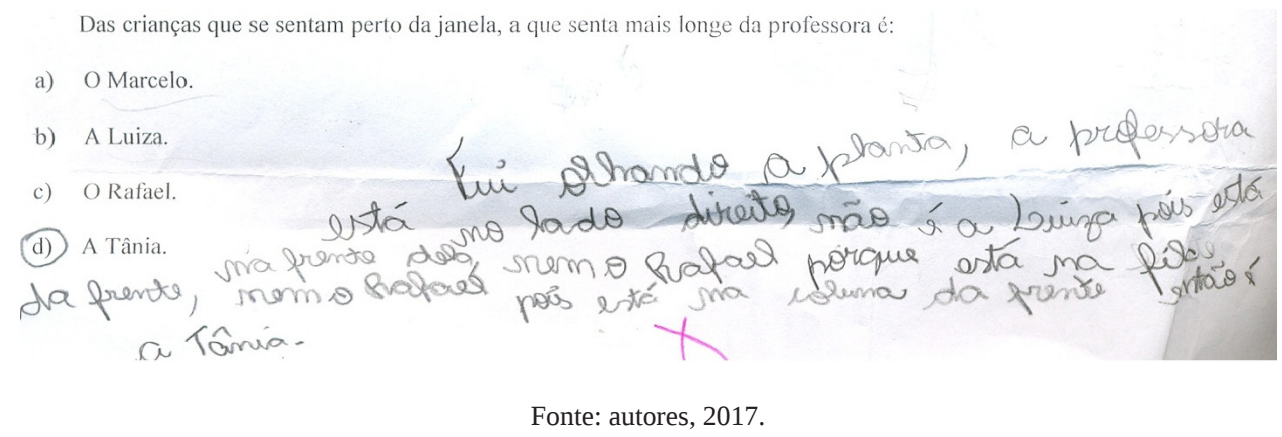

Destacamos que na maioria das questões os estudantes somente marcaram a resposta, percebeu-se durante a aplicação das questões que eles encontram muitas dificuldades em apresentar o desenvolvimento, em expor no papel o que realizaram para chegar às respostas, também podemos salientar que algumas questões não exigiam a aplicação de uma estratégia para resolver. 


\section{CONSIDERAÇÕES}

Os apontamentos realizados ao longo deste trabalho buscam destacar a importância de explorar a utilização de diferentes estratégias de resolução de problemas matemáticos, a qual estimula a curiosidade e prepara o estudante para lidar com novas situações sendo levado a pensar, conhecer, ousar e solucionar problemas matemáticos dentro e fora da escola.

Propormos a resolução de problemas nas atividades realizadas nas escolas parceiras ao projeto, pois acreditamos que para resolver problemas, o estudante necessita de diferentes maneiras de pensar, organizar, descobrir padrões, estabelecer conexões, construir relações. Deste modo, a utilização desta tendência de ensino, a partir da resolução de problemas no currículo de Matemática da educação básica é importante por ser um meio de construir e adquirir conhecimento e por ser um processo no qual o estudante consegue aplicar o que já havia sido construído previamente.

Salientamos que o trabalho com resolução de problemas, está sendo muito discutido, e com certeza, não é uma tarefa fácil de ser desenvolvida e utilizada pelos professores em sala de aula, devido a nossa própria formação. Porém as propostas que estão sendo desenvolvidas nas escolas possuem o propósito aperfeiçoar ainda mais o ensino de Matemática a partir da resolução de problemas.

Durante os encontros destacamos a satisfação dos estudantes em resolver problemas por seus próprios meios, a imagem que ele vai construindo de si mesmo, como alguém capaz de resolver problemas. Apontando que percebe-se claramente a partir das analises realizadas, que os estudantes passaram a utilizar diferentes estratégias para resolver os problemas. Pois como foi descrito ao longo do trabalho, no início de cada encontro as questões eram exploradas, mostrando para os estudantes as diferentes estratégias que poderiam ser utilizadas para resolução daquele problema.

Concluímos que é muito importante trabalhar, com os estudantes, diferentes raciocínios em diferentes contextos. Deste modo, estaremos possibilitando que nossas crianças ampliem os conceitos pertinentes ao campo conceitual e, consequentemente, ampliem suas competências para resolver, gradativamente, níveis mais sofisticados desses problemas. 


\section{REFERÊNCIAS}

ALVES, Rose Mary Fernandes. Uma análise da produção escrita de alunos do Ensino Médio em questões abertas de Matemática. Londrina, em 2006. Disponível em <http://www.uel.br/grupo-estudo/gepema/ Disserta\%E7\%F5es/2006\%20Rose\%20Mary\%20-\%20disserta\%E7\%E3o.pdf> Acesso em: 01 mai. 2019.

BRASIL. Secretaria de Educação Fundamental. Parâmetros Curriculares Nacionais: Matemática. Secretaria de Educação Fundamental. Brasília: MEC/SEF, 1998.

CAVALCANTI, Cláudia T. Diferentes Formas de Resolver Problemas. In: SMOLE, Kátia Stocco; DINIZ, Maria Ignez. Ler, escrever e resolver problemas: Habilidades básicas para aprender matemática. Editora Artmed: Porto Alegre, 2001.

DANTE, Luiz Roberto. Didática da Resolução de Problemas de Matemática. Editora Atica. 2002.

DANTE, Luiz Roberto. Formulação e resolução de problemas matemáticos: teoria de prática. Editora Ática. 2010.

FURLANETTO, Virginia. Explorando Estratégias Diferenciadas na Resolução de Problemas Matemáticos. Publicado em BDU - Biblioteca Digital da UNIVATES (http://www.univates.br/bdu). Acesso em: 01 mai. 2019.

GONÇALVES, Andreia Cláudia Jacinto. Desenvolvimento do sentido de número num contexto de resolução de problemas em alunos do $1^{\circ}$ Ciclo do Ensino Básico. Mestrado em Educação e Especialidade em Didáctica Matemática, 2008. Disponível em <http://www.esev.ipv.pt/mat1ciclo/textos/19637_Andreia_Goncalves.08[1]. pdf>. Acesso em: 01 mai. 2019.

POZO, Juan Ignácio (Org). A solução de Problemas: Aprender a resolver, resolver para aprender. Porto Alegre: Editora Artmed. 1998

SMOLE, Kátia Stocco, DINIZ, Maria Ignez. Ler, escrever e resolver problemas: Habilidades básicas para aprender matemática. Editora Artmed. 2001.

VALE, Isabel; PALHARES, Pedro; CABRITA, Isabel; BORRALHO, António. Os padrões no ensino e aprendizagem da álgebra. In: VALE, I. et al. (org.). Números e álgebra: na aprendizagem da matemática e na formação de professores. Portugal: Sociedade Portuguesa de Ciências da Educação. Seção de Educação Matemática, 2006, p. 193-211. 